\title{
Medium Overlays for improved Hardening of Micropropagated Potatoes
}

\section{Jennifer Crane and Harrison Hughes \\ Department of Horticulture, Colorado State University, Fort Collins, CO 80523}

Additional index words. Solarium tuberosum, tissue culture, paraffin, lanolin, vegetable fat

Abstract. Plantlets of Solarium tuberosum L. 'Russet Burbank', 'Sangre', and 'Centennial Russet' were grown in vitro from nodal cuttings. A medium overlay was used to reduce the humidity of the in vitro environment. This treatment was tested for its effect on plant growth and on the rate of water loss from detached leaves. The latter was assayed as indicative of hardening and consequent survival of plantlets once removed from in vitro culture. The paraffin medium overlay reduced the rate of water loss from detached leaves of cultured plantlets, but also reduced root growth.

Low survival rates and reduced growth rates of woody and herbaceous in vitro cultured plantlets accompany transfer to a potting mixture. These problems can be overcome by misting and gradual hardening of the plantlets in a greenhouse, a process that may require considerable time and expense (Anderson and Meagher, 1978). This time could be decreased by improving the hardiness of the plants before removal from culture (Wardle et al., 1983; Ziv et al., 1983). The objective of this study was to produce a propagule that can be transplanted directly to the field. These experiments were designed to examine the ability of various medium overlays to reduce the relative humidity of the in vitro microenvironment and evaluate the effects of these treatments on cultured potato plantlets. The influence of reduced relative humidity on hardening in vitro potato plantlets as determined by moisture loss from detached leaves was also observed.

'Russet Burbank', 'Centennial Russet', and 'Sangre' potato plantlets were grown from nodal cuttings on Murashige and Skoog (MS) medium (Murashige, 1974) with no hormones in glass jars (210-ml capacity) covered with Magenta B-caps. The medium contained $30 \mathrm{~g}$ sucrose/liter, $5.5 \mathrm{~g}$ agar/liter, and $\mathrm{pH}$ was adjusted to 5.7. Five nodal cuttings were grown in each jar containing 30 $\mathrm{ml}$ of medium. Cultural conditions were 25 $\pm 2 \mathrm{C}$ under $58 \mathrm{~mol} \cdot \mathrm{s}^{-1} \cdot \mathrm{m}^{-2}$ for $16 \mathrm{hr}$. Subcultures of nodal sections, excluding the terminal node, were made at 2 -week intervals.

Three materials poured over the agar surface were evaluated for their effects on growth of 'Sangre' potato plantlets (Expt. 1). All layered materials used were sterilized by au-

Received for publication 26 Sept. 1988. Funding was provided by the Colorado Agricultural Experiment Station (Project 604). The cost of publishing this paper was defrayed in part by the payment of page charges. Under postal regulations, this paper therefore must be hereby marked advertisement solely to indicate this fact. Burbank' toclaving. After autoclaving and before solidifying, the materials were poured over the agar surface in a transfer hood to form a layer » 2 to $3 \mathrm{~mm}$ thick on the solidified agar (MS). Medium nodal cuttings were planted through 1-mm holes made by using a heated needle in each covering. Plantlets were allowed to grow for 14 days and then were evaluated for height, number of nodes, number of roots, and root weight. General ob- servations of plant health were also made. The experimental design was a randomized complete block of three blocks with 15 samples-each. Data were analyzed using a statistical package that analyzes random and randomized complete-block designs (McKibben et al.,1980). The program provided ranked means with Duncan's new multiple range test for significance.

The influence of the paraffin medium overlay on plant growth was evaluated on 'Russet Burbank' and 'Centennial Russet' potatoes in Expt. 2. The experimental method was as in Expt. 1.

Experiment 3 was conducted to determine the effect of paraffin-covered medium on acclimation of the plantlets. These were cultured for 14 days. Leaves were detached and then placed abaxial side up on aluminum pans and held at $23 \mathrm{C}$. Weights were taken at 30min intervals for $3 \mathrm{hrs}$. Water loss was determined by the following formula: Water loss $(\%)=\left[\left(\right.\right.$ Fresh wt $\mathrm{T}_{1}-$ Dry wt $)-$ (Fresh wt $\mathrm{T}_{\mathrm{n}}-$ Dry wt) $] /\left(\right.$ Fresh wt $\mathrm{T}_{1}-$ Dry wt), where: $T_{1}=$ zero time, $T_{n}=$ observation time, and Dry wt $=$ tissue ovendried at $70 \mathrm{C}$ for $24 \mathrm{hr}$.

Relative humidity readings were taken using a Vaisala humidity indicator (Model HMI 31, Vaisala, Finland) inserted into the culture vessel. Readings were recorded once at the end of the 2-week culture period.

All three medium overlays were detrimen-

Table 1: Effects of three medium overlays on growth of 'Sangre' potato plantlets.

\begin{tabular}{lcccr}
\hline \hline Overlay & $\begin{array}{c}\text { Plant ht } \\
(\mathrm{cm})\end{array}$ & $\begin{array}{c}\text { No. } \\
\text { of nodes }\end{array}$ & $\begin{array}{c}\text { No. } \\
\text { of roots }\end{array}$ & $\begin{array}{r}\text { Root wt } \\
(\mathrm{mg})\end{array}$ \\
\hline Control & $40.2 \mathrm{a}$ & $3.7 \mathrm{ab}$ & $4.9 \mathrm{a}$ & $27.1 \mathrm{a}$ \\
Lanolin & $23.4 \mathrm{~b}$ & $3.2 \mathrm{bc}$ & $4.1 \mathrm{ab}$ & $5.50 \mathrm{~b}$ \\
Vegetable shortening & $14.8 \mathrm{~b}$ & $2.7 \mathrm{C}$ & $0.7 \mathrm{c}$ & $0.67 \mathrm{C}$ \\
Paraffin & $47.0 \mathrm{a}$ & $4.2 \mathrm{a}$ & $5.1 \mathrm{a}$ & $3.67 \mathrm{~b}$ \\
\hline
\end{tabular}

'Mean separation using Duncan's new multiple range test for significance at $P=0.05$. Means represent the average of 15 observations. Similar results were observed for 'Centennial Russet' and 'Russet

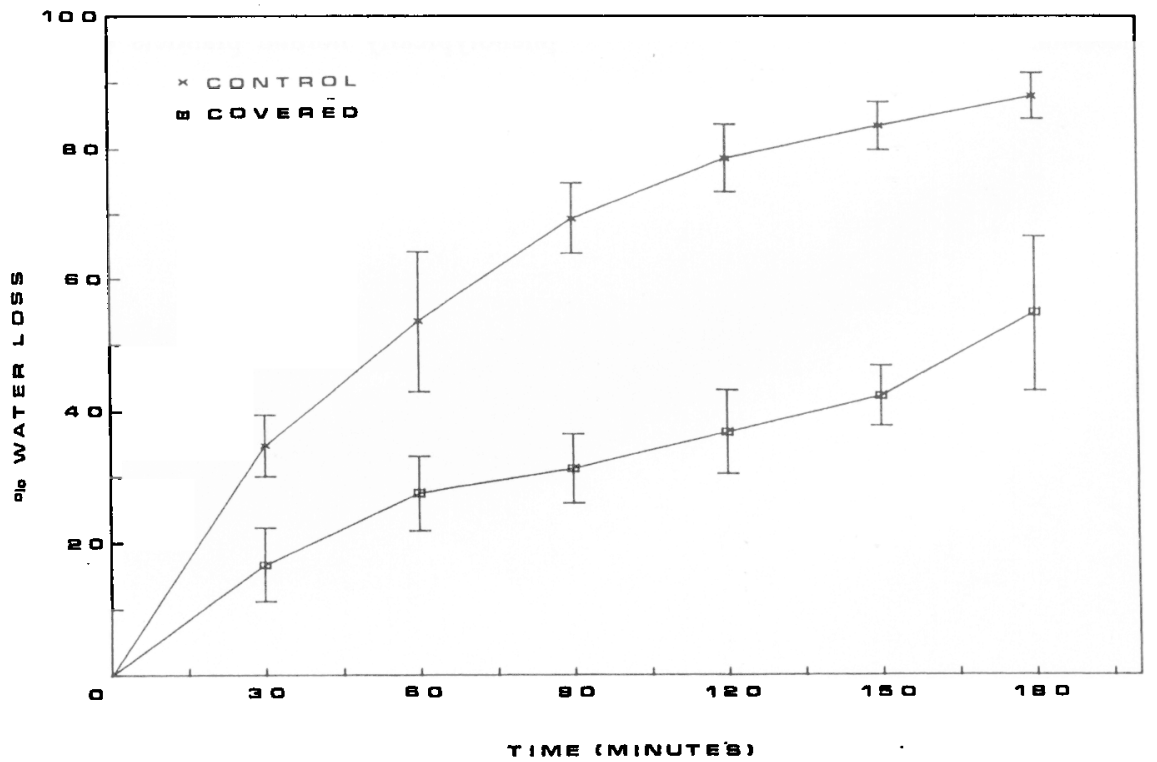

Fig. 1. Influence of a paraffin medium overlay on water loss from detached leaves of 'Russet Burbank' potato. Bars indicate the confidence interval for average water loss from all leaves for each of 10 blocks. Similar results were obtained for 'Centennial Russet' and 'Sangre'. 
tal to growth of potato plantlets (Table 1). Lanolin and vegetable shortening caused significant reductions in plant height and root weight. Similar results were obtained by Wardle et al. (1983) with cauliflower, a result that he attributed to reduced relative humidity. Thickening of the leaves and sterns was also noticed. The paraffin treatment caused a significant reduction in root weight, but did not otherwise affect growth.

There were no apparent effects on stem growth characteristics of 'Russet Burbank' or 'Centennial Russet' as a result of the paraffin treatment. Statistically, there was also no effect on root growth, although variability was quite high (data not shown).

The paraffin medium overlay used in the third experiment reduced relative humidity from $100 \%$ to $70 \%$. Reduction in water loss
(Fig. 1) for the potato plantlets grown under reduced humidity was comparable to that noted by Brainerd et al. (1981) and Brainerd and Fuchigami (1981) for in vitro-grown plum and apple plantlets that had been hardened for several days in the greenhouse.

The use of paraffin as a medium overlay improved resistance of detached leaves to water loss. Reduced relative humidity in vitro may result in improved cuticle formation or stomatal function; however, a medium overlay can reduce root growth.

\section{Literature Cited}

Anderson, C. and G.W. Meagher. 1978. Cost of propagating broccoli plants through tissue culture. HortScience 12:543-544.

Brainerd, K.E. and L.M. Fuchigami. 1981. Acclimatization of aseptically cultured apple plants to low relative humidity. J. Amer. Soc. Hort.
Sci. $106 \cdot 515-518$

Brainerd, K. E., L.M. Fuchigami, S. Kwiatkowski, and C.S. Clark. 1981. Leaf anatomy and water stress of aseptically cultured 'Pixy' plum grown under different environments. HortScience 16:173-175.

McKibben, G. H., W.A. Dickerson, and E.P. Lloyd. 1980. Interactive computer program for simple statistical designs. USDA. Sci. and Educ. Admin. Adv. in Agr. Tech. AAT-S-17.

Murashige, T. 1974. Plant propagation through tissue culture. Annu. Rev. Plant Phys. 25:135166.

Wardle, K., A. Quinland, and K.C. Short. 1983. In vitro acclimatization of aseptically cultured plantlets to humidity. J. Amer. Soc. Hort. Sci. 108:386-389

Ziv, M., G. Meir, and A.M. Malevy. 1983. Factors influencing the production of hardened glaucous carnation plantlets in vitro. Plant Cell, Tissue and Org. Cult. 2:55-65. 